\title{
Konsolidacija pamćenja u primarnoj nesanici
}

\section{Memory consolidation in primary insomnia}

\author{
Paula Pedić*
}

Sveučilište u Zadru, Zadar

"Dopisni autor:

Paula Pedić, univ. bacc. psych.

Sveučilište u Zadru

Mihovila Pavlinovića 1, 23000 Zadar

e-mail: ppedic0301@gmail.com

Sažetak. Pretpostavlja se da spavanje ima brojne funkcije, a jedna od njih je i konsolidacija pamćenja. Konsolidacija pamćenja je neurološki proces putem kojega se stvaraju trajni tragovi u dugoročnom pamćenju. Postavlja se pitanje što se događa s pamćenjem ako je spavanje poremećeno? Jedan od najčešćih poremećaja spavanja je primarna nesanica. Korpus dosadašnjih istraživanja pamćenja u primarnoj nesanici je ograničen, a znanstvena metoda ovih istraživanja različita, pa ne čudi da su dosadašnja istraživanja proceduralnog i deklarativnog pamćenja osoba s primarnom nesanicom polučila nesukladne rezultate. Cilj rada je prikazati odnos pamćenja i spavanja na primjeru primarne nesanice te sistematizirati rezultate dosadašnjih istraživanja.

Ključne riječi: konsolidacija; nesanica; pamćenje; spavanje

Abstract. It has been suggested that memory has many functions, with memory consolidation being one of them. Memory consolidation is a neurological process of making permanent memories. The question that arises is: what happens to memory if sleep is distorted? One of the most common sleeping disorders is primary insomnia. Not enough research has been done on the memory of patients with primary insomnia, and those existing research methods vary significantly, which leads to results inconsistencies. This review will focus on explaining the relationship between sleep and memory in primary insomnia and aims to give a brief overview of findings in existing literature.

Key words: consolidation; insomnia; memory; sleeping

http://hrcak.srce.hr/medicina 


\section{UVOD}

Spavanje je prirodno, reverzibilno stanje u kojemu je odgovor na vanjske podražaje smanjen, a koje se pojavljuje u pravilnim intervalima $i$ homeostatski je regulirao ${ }^{1}$. Može biti podijeljeno u dvije različite faze: faza REM (engl. rapid eye movement) i NREM (engl. non rapid eye movement) spavanja. REM i NREM spavanje povezani su sa specifičnim moždanim valovima i neuralnom aktivnošću. Za vrijeme REM spavanja svi voljni mišići, izuzev očnih, paralizirani su. REM spavanje popraćeno je moždanim valovima niske amplitude, frekvencije od $15-30 \mathrm{~Hz}$. Otprilike $20 \%$ vremena spavanja čovjek provede u stanju REM spavanja, iako valja napomenuti kako je količina REM spavanja negativno povezana s dobi. NREM spavanje okarakterizirano je valovima niske frekvencije, a visoke amplitude i može biti podijeljeno $u$ tri faze: prva faza je faza tranzicije iz stanja budnosti u stanje sna, odnosno iz beta (12 - $30 \mathrm{~Hz})$ i gama $(25-100 \mathrm{~Hz}$ ) valova u više sinkronizirane, ali sporije alfa-valove $(8-13 \mathrm{~Hz})$, a potom i u teta-valove $(4-7 \mathrm{~Hz})$. U drugoj fazi dominiraju teta-valovi, ali se pojavljuju s K-kompleksima i vretenima spavanja. Posljednja faza NREM spavanja naziva se sporovalnim spavanjem, budući da se u njoj pojavljuju najsporiji delta valovi, frekvencije $0.5-4 \mathrm{~Hz}$. Kod zdravih osoba ove faze spavanja sukcesivno se izmjenjuju od faze 1 NREM spavanja do REM spavanja, a onda opet iz REM spavanja u fazu 1 NREM spavanja. Jedan ciklus spavanja obično traje od 90 110 minuta $^{1}$. Pretpostavlja se da spavanje ima brojne funkcije, a neke od njih su konzervacija energije, modulacija imunog odgovora i konsolidacija pamćenja ${ }^{2}$. Konsolidacija pamćenja je neurološki proces putem kojega se stvaraju trajni tragovi (engrami) u dugoročnom pamćenju ${ }^{1}$. Aktivnost hipokampusa tijekom spavanja posebice je važna za konsolidaciju pamćenja. Naime, hipokampus povezuje informacije iz različitih kortikalnih područja za vrijeme faze učenja te in spavanjem konsolidira u ne-hipokampalnoj lokaciji u neokorteksu stvarajući tako engrame u dugoročnom pamćenju. Ako spavanje ima ključnu ulogu u konsolidaciji pamćenja, postavlja se pitanje što se događa s pamćenjem ako je spavanje poremećeno? Poremećaji spavanja, prema klasi- fikaciji MKB-10 mogu biti klasificirani kao kvantitativni i kvalitativni. Kvantitativni poremećaji nagona za spavanje javljaju se u obliku smanjenog nagona za spavanjem (neorganska nesanica) i povećanja ovog nagona (neorganska pospanost). Kvalitativni poremećaji nagona za spavanje znatno su brojniji, a neki od njih su somnambulizam, enureza, bruksizam i pavor nocturnus. Pamćenje osoba s neorganskom nesanicom još uvijek je relativno neistraženo, a različite metode i kriteriji za dijagnostiku nesanice uvelike otežavaju ge-

Uspješnost deklarativnog i proceduralnog pamćenja kod osoba s neorganskom nesanicom uvelike ovisi o i tome je li između perioda učenja i dosjećanja implementiran interferencijski zadatak ili ne. $U$ recentnoj studiji zabilježena je atenuirana konsolidacija deklarativnog pamćenja samo onda kada je dosjećanju prethodio interferencijski zadatak.

neralizaciju rezultata dosadašnjih istraživanja. Stoga je cilj ovog preglednog rada pružiti sistematičan uvid u dosadašnja istraživanja deklarativnog i proceduralnog pamćenja osoba s neorganskom nesanicom, s posebnim naglaskom na metodu istraživanja.

\section{PRIMARNA NESANICA}

Nesanica (lat. insomnia, F51.0, prema MKB-10) označava stanje deficitarne količine i kvalitete spavanja. Pojavljuje se kao smetnja prilikom uspavljivanja i/ili održavanja spavanja i/ili nedovoljnog spavanja. Nesanica je jedan od poremećaja spavanja s najvećom prevalencijom u općoj populaciji, a češće od nje pate žene i osobe starije životne dobi ${ }^{3}$. Uzroci mogu biti brojni, ali najčešće je ona posljedica užurbanog i stresnog načina života ${ }^{3}$. Kriteriji za dijagnostiku nesanice su brojni. Dijagnostika prvenstveno počiva na samoizvještajima, iako se poremećaj može dijagnosticirati i polisomnografskim metodama. Nesanice se mogu podijeliti na primarne i sekundarne nesanice te nesanice povezane $s$ drugim poremećajima spavanja, ovisno o etiologiji bolesti ${ }^{3}$. U ovom preglednom radu govorit će se o primarnoj ili neorganskoj nesanici, odnosno nesanici koji se javlja kao subjektivna percepcija poremećaja us- 
pavljivanja, trajanja i kvalitete sna, unatoč postojanju svih uvjeta za spavanje, a koja nije posljedica ili simptom nekih kroničnih bolesti.

\section{KONSOLIDACIJA PAMĆENJA}

Ljudsko se pamćenje, prema modelu Atkinsona i Shiffrina ${ }^{4}$ može promatrati kao trokomponentni sustav sastavljen iz osjetnog, kratkoročnog i dugoročnog pamćenja. Pretpostavlja se da se obrada nove informacije odvija upravo spomenutom sekvencom, odnosno da, ovisno o modalitetu u kojem je informacija zadana, informacija prolazi kroz osjetno skladište u kratkoročno pamćenje, a onda iz kratkoročnog u dugoročno pamćenje. Međutim, da bi se informacija doista „premjestila" iz privremenog, kratkoročnog u trajno, dugoročno skladište potreban je period konsolidacije. Konsolidacija pamćenja je neurološki proces kojim se informacija, privremeno pohranjena $u$ hipokampusu, redistribuira u neokortikalna područja u funkciji vremena. U ovom procesu ključnu ulogu ima upravo hipokampus, a da je to tako, pokazano je još u studiji slučaja pacijenta H. M. U nadi da će mu se smanjiti simptomi epilepsije, ovome su pacijentu bilateralno uklonjeni anteriorni dijelovi temporalnog režnja ${ }^{5}$. lako je operacija pomogla u reduciranju epileptičnih napadaja, H. M. je postao nesposoban učiti nove materijale. Ovakva anterogradna amnezija pokazala se pervazivnom, budući da H. M. nije bio sposoban naučiti nove informacije neovisno o tome jesu li bile semantičkog ili epizodičkog karaktera. H. M. se nije sjećao događaja koji su se dogodili neposredno prije operacije, ali se sjećao onih događaja koji su mu se dogodili ranije u životu ${ }^{5}$. Budući da se nije mogao sjetiti informacija koje je kodirao neposredno prije operacije, pojavila se pretpostavka da svaka informacija mora proći kroz proces konsolidacije kako bi postala dijelom dugoročnog skladišta, a kako mu je operacijom odstranjen hipokampus pretpostavilo se da je upravo on ključan u konsolidaciji pamćenja.

\section{ULOGA SPAVANJA U KONSOLIDACIJI PAMĆENJA}

Uloga spavanja u konsolidaciji pamćenja očita je $\mathrm{u}$ istraživanjima u kojima se testiralo pamćenje sudionika ovisno o tome jesu li nakon zadatka učenja u jednakim vremenskim intervalima spavali ili bili u budnom stanju ${ }^{1}$. Naime, oni sudionici kod kojih je nakon perioda učenja uslijedio period spavanja imali su bolje rezultate na testu dosjećanja od onih koji nisu spavali nakon učenja. Točan način na koji spavanje sudjeluje u konsolidaciji pamćenja još nije poznat, međutim tri su osnovne hipoteze kojima se objašnjava uloga REM i NREM spavanja u konsolidaciji pamćenja ${ }^{1}$. Prva hipoteza naziva se hipotezom dualnog procesiranja. Ovim se hipotezom pretpostavlja da NREM spavanje facilitira konsolidaciju deklarativnih, a REM spavanje proceduralnih informacija. S druge strane, sekvencijalnom hipotezom tvrdi se da je sukcesivna izmjena NREM i REM epoha spavanja ključna u konsolidaciji i deklarativnog i proceduralnog spavanja. Naposljetku, hipotezom aktivne konsolidacije na neki način pomirene su prethodne hipoteze. Naime, prema ovoj hipotezi REM i NREM epohe spavanja imaju komplementarnu ulogu u konsolidaciji pamćenja, ali deklarativno i proceduralno pamćenje ima različite koristi od ovih faza spavanja. Polisomnografske metode pokazuju da pacijenti s primarnom nesanicom imaju reduciranu količinu sporovalnog spavanja, a povećanu količinu vremena provedu u prvoj fazi NREM spavanja ${ }^{6}$. S obzirom na rečeno, a u pogledu osnovnih hipoteza odnosa NREM i REM spavanja i pamćenja tri su moguća ishoda:

1. Prema hipotezi dualnog procesiranja za pretpostaviti je da proceduralno pamćenje osoba s primarnom nesanicom neće biti narušeno, ali će biti narušeno deklarativno pamćenje.

2. Prema sekvencijalnoj hipotezi i deklarativno i proceduralno pamćenje će biti narušeno kod osoba s primarnom nesanicom.

3. Prema hipotezi aktivne konsolidacije, obje vrste pamćenja bit će narušene, ali će deficiti pamćenja biti evidentniji u deklarativnim, nego u proceduralnim zadacima pamćenja.

DEKLARATIVNO I PROCEDURALNO PAMĆENJE OSOBA S PRIMARNOM NESANICOM

Dosadašnja istraživanja deklarativnog i proceduralnog pamćenja kod osoba s primarnom nesanicom polučila su nekonzistentnim rezultatima, međutim, rezultati uglavnom ili nisu pokazali ili 
su pokazali minimalne razlike u pamćenju ovih sudionika u usporedbi s kontrolnim, zdravim sudionicima. Ono što valja primijetiti jest da su gotovo sva prvotna istraživanja pamćenja kod osoba s nesanicom imale jedan velik metodološki nedostatak te je njihova relevantnost upitna. Naime, u ovim istraživanjima pamćenje je ispitivano odmah po učenju određenih materijala, dakle bez da je između učenja i dosjećanja umetnut period spavanja. Prvo istraživanje koje je ovaj nedostatak ispravilo je ono Backhausa, Borna, Hoeckesfelda i sur. (2007) ${ }^{8}$. U ovom istraživanju svi su sudionici podijeljeni u dvije skupine - oni s primarnom nesanicom i oni bez primarne nesanice (kontrolna grupa). Sudionici su prvo (navečer) rješavali test učenja parova riječi. Test se sastojao od 40 parova imenica na njemačkom jeziku, a svaki je par riječi bio prezentiran na ekranu 5 sekundi. Nakon prezentacije svih parova riječi sudionicima su bile prikazane po jedna riječ iz para, a oni su se morali dosjetiti riječi s kojom je ta riječ bila uparena. Intergrupne razlike u dosjećanju nisu utvrđene. Nakon toga uslijedio je period spavanja, a potom je sudionicima ponovljeno ispitivanje pamćenja riječi iz para. Ovog puta sudionici iz kontrolne grupe postigli su značajno bolje rezultate od sudionika s primarnom nesanicom, iako se pamćenje obje grupe generalno popravilo u odnosu na prvotno ispitivanje. Proceduralno pamćenje ispitivano je zadatkom učenja crtanja zrcalne zvijezde, a procedura je bila ista kao i u zadatku deklarativnog pamćenja. Sudionici iz kontrolne grupe i sudionici s primarnom nesanicom također se nisu razlikovali u prvotnom ispitivanju učenja crtanja zrcalne zvijezde, ali niti prilikom drugog ispitivanja, nakon konsolidacije pamćenja. Ovi rezultati idu u prilog hipotezi dualnog procesiranja, ali valja spomenuti i nekoliko nedostataka ovog istraživanja. Prvi nedostatak proizlazi iz same eksperimentalne intervencije $u$ pogledu ispitivanja deklarativnog pamćenja. Naime, nakon testa učenja riječi iz para eksperimentatoru su na ekranu bili prezentirani samo parovi riječi koje je sudionik točno povezao. To znači da nakon perioda spavanja i ponovnog testiranja deklarativnog pamćenja istraživači nisu mogli raščlaniti jesu li sudionici iz kontrolne grupe postigli bolje rezultate od sudionika s primarnom nesanicom zato što su poboljšali izvedbu (zapamtili još parova riječi) ili su samo zaboravili manje parova riječi od sudionika s primarnom nesanicom. Drugi nedostatak krije se u tome što sekvenca učenjespavanje-dosjećanje nije uspoređena sa sekvencom učenje-budnost-dosjećanje jer bi se tako moglo direktno zaključivati o ulozi spavanja u konsolidiranju pamćenja. U istraživanju Nissena, Kloepfera, Feigea i sur. (2011) ${ }^{9}$ ovaj je problem također adresiran te je sukladno tome prilagođen eksperimentalni nacrt istraživanja. Drugim riječima, uspoređen je učinak sudionika s nesanicom i

Prijedlog za buduća istraživanja svakako je uključiti i mjeru metamemorije u istraživačkim nacrtima. Budući da je pamćenje neophodno za svakodnevno funkcioniranje, znanje o osobnom pamćenju bilo bi vrlo korisno u prevenciji nezgoda uzrokovanih narušenim pamćenjem kod osoba koje pate od primarne nesanice.

kontrolnih sudionika u dvama uvjetima: uvjet spavanja i uvjet budnosti. Rezultati su se pokazali sukladnima s općim konceptom konsolidacije pamćenja: veća poboljšanja na zadacima proceduralnog i deklarativnog pamćenja evidentirana su kod onih sudionika koji su bili u uvjetu spavanja. Ovaj nalaz odnosi se i na sudionike iz kontrolne skupine, kao i na one s primarnom nesanicom. Međutim, ako usporedimo upravo te dvije grupe sudionika, rezultati ukazuju na to da je to poboljšanje u pamćenju proceduralnih informacija manje kod osobe s primarnom nesanicom u odnosu na zdrave sudionike, a poboljšanje deklarativnog pamćenja ne razlikuje se statistički značajno među ovim sudionicima. Zanimljivo je pitanje deklarativnog pamćenja u ovom istraživanju budući da su rezultati različiti onima Backhausa i Borna, Hoeckesfelda i sur. (2006). Jedno moguće objašnjenje ovih nesukladnih rezultata po pitanju deklarativnog pamćenja možda proizlazi iz činjenice da je u potonjem istraživanju korišten test učenja parova riječi, a koji je više ovisan o spavanju. ${ }^{10}$ Još jedno objašnjenje je „efekt prve noći”. Naime, podaci iz istraživanja Nissena i suradnika ${ }^{9}$ bazirani su na samo jednoj eksperimentalnoj noći, a u polisomnografskim zapisima evidentno je kako je tijekom prve noći u laboratoriju efikasnost spavanja snižena, periodi budnosti su produženi i sudi- 
onici manje vremena provedu u REM fazi spavanja ${ }^{11}$. Drugim riječima, iako intergrupna razlika u deklarativnom pamćenju u ovom istraživanju nije pronađena, možda bi se pojavila da su sudionici proveli duže od jedne noći u laboratoriju. Uspješnost deklarativnog i proceduralnog pamćenja kod osoba s neorganskom nesanicom uvelike ovisi o i tome je li između perioda učenja i dosjećanja umetnut ometajući zadatak ili ne. Griessenberger, Heib, Lechinger i sur. (2013) ${ }^{12}$ provjerili su ovu tezu u svojem istraživanju. Postupak istraživanja bio je takav da su sudionici prije spavanja učili zadatak iz domene deklarativnog (učenje parova riječi) i proceduralnog (učenje ritma lupkanja prstom) pamćenja, ali prije ispitivanja dosjećanja polovici sudionika zadan je ometajući zadatak. Ometajući zadatak sastojao se u učenju novih parova riječi (deklarativno pamćenje), odnosno novih ritmova lupkanja prstom (proceduralno pamćenje). Zabilježena je oslabljena konsolidacija deklarativnog pamćenja kod osoba $\mathrm{s}$ neorganskom nesanicom, ali samo onda kada je dosjećanju prethodio ometajući zadatak. Nije utvrđeno oslabljenje proceduralnog pamćenja, neovisno o tome jesu li ili nisu bili izloženi ometajućem zadatku pamćenja. Ovakvi rezultati djelomično su u skladu s hipotezom dualnog procesiranja.

Sumirano, u istraživanjima deklarativnog i proceduralnog pamćenja osoba s primarnom nesanicom uzorci su često heterogeni prema dobi, komorbiditetu i obrazovanju. Način primjene i interpretacija istih testova pamćenja razlikuju se od istraživanja do istraživanja. Stoga se u budućim istraživanjima preporučuje inspekcija čimbenika koji mogu utjecati na pamćenje sudionika, a onda i njihova kontrola, kako ne bi zamaglili efekt jedine nezavisne varijable od interesa - nesanice.

\section{ZAKLJUČAK}

Iz svega navedenoga može se zaključiti da je ispitivanje deklarativnog i proceduralnog pamćenja kod osoba s primarnom nesanicom još uvijek $u$ svojim počecima. Rezultati istraživanja pamćenja pokazali su se nesukladnima, a razlog tome mož- da je različita metoda, posebice u pogledu eksperimentalnog nacrta pojedinih istraživanja kao i prirode zadataka pamćenja. Da su istraživanja na ovu temu još uvijek u svojim počecima vidi se i iz toga što još nije došlo do faze replikacije istraživanja i provjere rezultata pojedinih istraživanja. Jedan od prijedloga za buduća istraživanja svakako je uključiti i mjeru metamemorije u istraživačkim nacrtima. Budući da je pamćenje neophodno za svakodnevno funkcioniranje, a ako je ono doista oslabljeno kod osoba koje pate od primarne nesanice, onda bi njihovo znanje o osobnom pamćenju bilo vrlo korisno u prevenciji potencijalnih nezgoda uzrokovanih narušenim pamćenjem.

Izjava o sukobu interesa: Autorica izjavljuje da ne postoji sukob interesa.

\section{LITERATURA}

1. Rasch B, Born J. About sleep's role in memory. Physiol Rev 2013;93:681-766.

2. Zielinski MR, McKenna JT, McCarley RW. Functions and Mechanisms of Sleep. AIMS Neurosci 2016;3:67-104.

3. Begić D. Poremećaji spavanja i njihovo liječenje. Medicus 2017;26:209-14.

4. Atkinson RC, Shiffrin RM. The control of short-term memory. Sci Am 1971;225:82-90.

5. Squire LR. The legacy of patient H.M. for neuroscience. Neuron 2009;61:6-9.

6. Walsh JK. Enhanement of slow wave sleep: implications for insomnia. J Clin Sleep Med 2009;5:27-32.

7. Sateia MJ, Doghramji K, Hauri PJ, Morin CM. Evaluation of chronic insomnia. An American Academy of Sleep Medicine review. Sleep 2000;23:243-308.

8. Backaus J, Born J, Hoeckesfeld R, Fokuhl S, Hohagen F, Junghanns K. Midlife decline in declarative memory consolidation is correlated with a decline in slow wave sleep. Learn Mem 2007;14:336-41.

9. Nissen C, Kloepfer C, Feige B, Piosczyk H, Spiegelhalder $\mathrm{K}$, Voderholzer $\mathrm{U}$ et al. Sleep-related memory consolidation in primary insomnia. J Sleep Res 2011;20:129-36.

10. Rauchs G, Desgranges B, Foret J, Eustache, F. The relationships between memory systems and sleep stages. J. Sleep Res 2005;14:123-40.

11. Agnew HW, Webb WB, Williams RL. The first night effect, an EEF study of sleep. Psychophysiol 1966;2:263-66.

12. Griessenberger $H$, Heib DPJ, Lechinger J, Luketina N, Petzka M, Moeckel T et al. Susceptibility to Declarative Memory Interference is Pronounced in Primary Insomnia. Plos One [Internet]. 2013;8. [cited 2019 Feb14]. Available from: https://journals.plos.org/plosone/ article?id=10.1371/journal. pone.0057394\#references. 